\title{
Pathology of poverty: the need for quality improvement efforts to address social determinants of health
}

\author{
Andrew S Boozary, ${ }^{1,2}$ Kaveh G Shojania ${ }^{3}$
}

\begin{abstract}
${ }^{1}$ Department of Family and Community Medicine, University of Toronto, Toronto, Ontario, Canada

${ }^{2}$ Department of Health Policy and Management, Harvard School of Public Health, Boston, Massachusetts, USA ${ }^{3}$ Department of Medicine, Sunnybrook Health Sciences Centre and the University of Toronto, Toronto, Ontario, Canada
\end{abstract}

\section{Correspondence to} Dr Kaveh G Shojania, Department of Medicine, Sunnybrook Health Sciences Centre and the University of Toronto, Toronto, ON M4N 3M5, Canada;

kaveh.shojania@sunnybrook.ca

Accepted 15 February 2018 Published Online First 6 March 2018

\section{SLinked}

- http://dx.doi.org/10.1136/ bmjqs-2017-006968 - http://dx.doi.org/10.1136/ bmjqs-2017-007168

Check for updates

To cite: Boozary AS, Shojania KG. BMJ Qual Saf 2018;27:421-424.
A massive body of literature characterises the impact of poverty on health outcomes. In 1817, Rene Villermé, a young French surgeon (and later economist-cum-social commentator), demonstrated stark differences in life expectancy across Parisian neighbourhoods or arondissements. ${ }^{1}$ This demonstration of disparities in basic health outcomes across income levels helped configure our early understanding of the 'social determinants of health'. These determinants refer to the conditions in which people are born, grow, live, work and age, including income, housing and education, among others. Even 200 years after Villermé, with so many technological advances both within and outside of healthcare, the unequal distribution of resources across society continues to exert tremendous influence on the health outcomes of individuals and their communities. ${ }^{2-5}$

\section{UNDERAPPRECIATED IMPACTS OF POVERTY AS A COGNITIVE IMPEDIMENT}

In this issue of BMJ Quality and Safety, two papers draw attention to just some of the ways in which poverty directly affects the types of issues many in quality improvement (QI) aim to address. In their viewpoint article on the importance of simplifying care when managing chronic diseases for patients living in poverty, Nwadiuko and Sander describe a patient who will regrettably seem all too familiar to many primary care providers. ${ }^{6}$ The patient, a 52-year-old mother, has chronic medical conditions which include cirrhosis due to hepatitis C, uterine fibroids, hypertension and migraines. She struggles to manage these medical problems while also serving as the primary caregiver of a daughter with bipolar disease, along with nine grandchildren. She has been mired in poverty for years. And, on the day of this clinic visit, her primary care physician learns that she has recently been evicted from her home. Her resilience in simply making it to the appointment is striking enough, yet the authors argue that, as the therapeutic burden for patients with comorbidities has increased, we have failed to deliver care that accounts for poverty's detrimental effect on mental bandwidth-roughly regarded as the ability of an individual to cope with new challenges demanding mental attention or focus.

The authors ground their argument in the findings of an unusual, yet elegant and compelling study published in Science in 2013 by Mani and colleagues. ${ }^{7}$ These authors wrote in the introduction to their paper: 'The poor must manage sporadic income, juggle expenses, and make difficult tradeoffs. Even when not actually making a financial decision, these preoccupations can be present and distracting.' They set out to show that poverty induces negative effects on cognition through this constant, background distraction and taxing of energy. To demonstrate the impact of this cognitive tax imposed by poverty, Mani et al conducted a related set of laboratory and field experiments. The laboratory experiment consisted of asking richer and poorer participants (drawn from shoppers at a New Jersey mall) to think about problems encapsulating everyday financial demands. They designed the experiments to show that cognitive performance declined for arithmetic problems involving monetary 
sums expected to trigger subconscious associations with real-world concerns. In a nutshell, they show that problems with similarly sized financial challenges produce different cognitive impacts on the poor and the rich independent of innate arithmetic ability.

Mani and colleagues acknowledge various possible alternate interpretations of these laboratory studies, so they follow them up with a novel field investigation involving Indian sugarcane farmers. They chose this group because Indian sugarcane farmers routinely experience cycles of poverty-poor before harvest and richer (or, at least, less poor) after-allowing the authors to compare cognitive capacity for the same farmer when poor (preharvest) versus richer (postharvest). They observed significant drops in cognitive performance (roughly 13 IQ points) before the harvest versus afterwards. ${ }^{7}$ As to how such a change might alter decision-making, the authors frame the magnitude of drop as comparable to the decline in cognitive performance following a full night without sleep. Importantly, other studies have documented similar cognitive ill effects from neighbourhood violence, such that, for instance, background levels of violence or recent violent incidents in a neighbourhood produce detectable negative impacts on children's cognitive function. ${ }^{8-10}$ Whether directly or by proxy, poverty produces substantial adverse effects which healthcare systems have been ill suited to remedy.

As poverty might siphon off the cognitive resources needed for personal choices and decisions, ${ }^{7-10}$ Nwadiuko and Sander suggest that this might disadvantage poorer patients everywhere from medication compliance to making (and keeping) appointments. Ultimately, we are all prone to errors-in our work and our personal lives; this is one of the premises of the patient safety field and human factor engineering. But, poverty leaves less room for error, so that a mistake which might entail only a minor inconvenience for many people could create catastrophic consequences for a person living in poverty. ${ }^{11}$

\section{POVERTY AS PART OF THE STORY BEHIND THE 'CLINIC NO-SHOW'}

An empirical study also in this issue by Wallace and colleagues ${ }^{12}$ helps illustrate how the transaction costs of poverty might play out in terms of seemingly mundane aspects of healthcare, such as clinic attendance. With clinic non-attendance rates nearing 30\% in their urban paediatric clinic in Pennsylvania, the authors sought to better understand some of the transportation and patient factors associated with missed appointments. While previous studies have shown a relationship between social deprivation and clinic attendance, ${ }^{13-15}$ this impressive study incorporated Geographic Information Systems data and Google's Travel Calculator to delve into the details of driving and public transportation. In their analysis of 51580 scheduled appointments spanning over 20 zip codes, the authors found a significant interaction between travel time and income in terms of the likelihood of missing a paediatric appointment. Patients in the lowest quartile of income who also faced the longest quartile of travel time by bus were approximately 50\% more likely (OR 1.55; $\mathrm{P}<0.01)$ to miss their appointment compared with patients in the same quartile of income yet residing in one of the zip codes with the shortest quartile of public transportation time. Because some poor patients might travel to the clinic by car, the authors performed the same analysis for driving estimates and the association between non-arrival and travel time was again only seen for patients living in the poorest zip codes.

\section{POVERTY AS THE LEAST APPRECIATED 'SYSTEM PROBLEM'}

What realistically can those working in QI do with findings such as those of Wallace and colleagues ${ }^{12}$ or the perspective offered by Nwadiuko and Sander ${ }^{6}$ ? First, it may be worth reconciling these findings with our notions of 'personal responsibility'. This is particularly important for those interested in healthcare quality, as one of the central features of the patient safety movement and QI more generally consists of the 'system perspective'. ${ }^{16}$ Instead of blaming individuals-patients or providers-for bad outcomes, exhorting providers to be more careful or work harder, patients to take more responsibility for their care, and so on, we look for the latent defects in the design of the healthcare system, which set the stage for so many bad outcomes.

Frameworks for root cause analysis and Ishikawa ('fishbone') diagrams present users with categories of system problems to consider-infrastructure issues; staffing levels; provider factors such as knowledge, skills, memory, attitudes; and 'patient factors'. Typical patient factors considered in these contexts include expectations and attitudes. Yet, poverty surely counts as the proverbial elephant in the room among contributing patient factors for so many issues affecting chronic disease management and quality problems more generally. A recent commentary by prominent patient safety experts calls for rethinking root cause analysis with a greater focus on the 'patient journey' across care settings, rather than restricting adverse event investigation to a single setting of care. ${ }^{17}$ For many patients, their journeys across settings of care cannot be understood, never mind improved, without attention to the socioeconomic context in which they occur.

Another point, which Wallace and colleagues note in their paper, ${ }^{12}$ is that certain policies, such as 'free parking', though aimed at improving the patient experience tend to aid relatively affluent patients while providing little benefit to those in poverty, since they will less often have cars to park. We can hopefully avoid such unintended consequences by involving a broader group of patients in the design process. Coproduction of health services by patients and providers has begun 
to receive much overdue attention. ${ }^{18} 19$ However, we need to ensure that, in pursuing this path, we engage patients from more diverse socioeconomic and ethnic/ racial backgrounds. ${ }^{20} 21$

Furthermore, just as the field of behavioural economics is upending traditional economic models of idealised, hyper-rational decision-making agents, integrating more of these behavioural insights in the way we design, deliver and evaluate healthcare programmes might help produce more effective and equitable healthcare delivery models. As a real-world example, work by Berkowitz et al showed that when primary care patients were screened for basic unmet needs such as food and housing as part of the Health Leads programme, and then paired with an advocate to help gain these resources, patients experienced subsequent improvements in blood pressure and lipid levels. ${ }^{22}$ And on the prospect of 'liberating mental bandwidth' as recommended by Nwadiuko and Sander, a study by Redelmeier and colleagues demonstrated that small reductions in relative poverty through welfare payments actually mitigated risky behaviours and injuries among low-income mothers with dependent children. ${ }^{23}$ To be sure, we will never 'nudge ${ }^{24-26}$ patients out of poverty. But applying behavioural economic theories in clinical practice has shown some promise and will likely produce even greater impact if we fully acknowledge and take the time to understand the socioeconomic conditions which shape the lives of our patients.

\section{EQUITY AND BREAKING DOWN SILOS}

The US Institute of Medicine defines quality in terms of six dimensions ${ }^{27}$ : safety (avoiding harm from medical care), effectiveness (providing aspects of care with proven benefit), patient-centredness (providing care respectful of and responsive to patient preferences, needs and values), timeliness, efficiency (avoiding waste) and equity-the provision of care that does not vary in quality because of personal characteristics such as gender, ethnicity, geographic location and socioeconomic status. Each of these dimensions has enjoyed its day in the sun in almost 20 years since the launch of the quality movement with the Institute of Medicine report, To Err is Human, ${ }^{28}$ with the notable exception of equity.

Ironically, one of the commonly used tools in QI, the Pareto chart, ${ }^{29-31}$ owes its name to the 19th century Italian economist, Vilfredo Pareto, who first pointed out that a minority of citizens hold the majority of a society's wealth. In 1937, Juran applied this observation to defects in industrial processes, stating that $80 \%$ of the problems are caused by $20 \%$ of the defects. Juran argued that focusing on that $20 \%$ could achieve large improvements with minimal effort. He dubbed this the Pareto Principle. ${ }^{29}$ Despite this early connection between QI and the study of economic inequalities, as well as the clear, ongoing importance of socioeconomic factors in determining health outcomes, we in QI have too often ignored this entire domain.

It is tempting to think, as we work away on preventing readmissions to hospital ${ }^{31-36}$ or the overuse of non-beneficial services, ${ }^{37-40}$ that someone else will work on the many glaring problems related to poverty and inequitable access to crucial resources. Yet, if we in QI, who espouse equity as a goal, do not take on these problems (or join others already tackling them), who will?

We often stress in QI the importance of multidisciplinary teams-breaking down silos within and across health professions and disciplines. Many of the most important quality problems faced in healthcare likely require breaking down silos even further-between healthcare and other social services. It is difficult to imagine successfully addressing current crises, such as the opiate epidemic and adequate access to mental health services, as well as impending crises related to the ageing population or a major pandemic, without collaboration between actors within the healthcare sector and those working in other social sectors, such as public housing, transportation, schools and the criminal justice system, among others. Moreover, a growing evidence base demonstrates that increased spending on social services outside of healthcare can lead to concrete improvements in health outcomes. ${ }^{41-43}$

If we are to do any better than Villermé, we in QI must partner with patients, communities and those working in social sectors outside healthcare to tackle these problems-poverty in itself and its many attendant adverse effects-for our most disadvantaged patients and our fellow human beings.

Contributors ASB and KGS both contributed to the conception of the paper; they both critically read and modified subsequent drafts and approved the final version. KGS is an editor of $B M J$ Quality \& Safety.

Funding This research received no specific grant from any funding agency in the public, commercial or not-for-profit sectors.

\section{Competing interests None declared.}

Provenance and peer review Commissioned; internally peer reviewed.

(C) Article author(s) (or their employer(s) unless otherwise stated in the text of the article) 2018. All rights reserved. No commercial use is permitted unless otherwise expressly granted.

\section{REFERENCES}

1 Villermé LR. De la mortalité dans les divers quartiers de la ville de Paris, et des causes qui la rendent très différente dans plusiers d'entre aux, ansi que les divers quartiers de beaucoup de grandes villes. Annales d'Hygiène Publique et de Médecine Légale 1830;3:294-341.

2 . et al Department of Health and Social Security In: Black, chairman D, Morris JN, Townsend P, Smith CS, . Inequalities in health. Report of a research working group. London: DHSS, 1980.

3 Sir Douglas Black. BMJ 2002;325:661. 
4 Commission on the Social Determinants of Health. Closing the gap in a generation: Health equity through action on the social determinants of health. final report of the commission on social determinants of health. Geneva, Switzerland: World Health Organization, 2008.

5 Marmot M, Friel S, Bell R, et al. Closing the gap in a generation: health equity through action on the social determinants of health. Lancet 2008;372:1661-9.

6 Nwadiuko J, Sander LD. Simplifying care: when is the treatment burden too much for patients living in poverty? BMJ Qual Saf 2018;27:484-7.

7 Mani A, Mullainathan S, Shafir E, et al. Poverty impedes cognitive function. Science 2013;341:976-80.

8 Sharkey PT, Tirado-Strayer N, Papachristos AV, et al. The effect of local violence on children's attention and impulse control. Am J Public Health 2012;102:2287-93.

9 Sharkey P. The acute effect of local homicides on children's cognitive performance. Proc Natl Acad Sci U S A 2010;107:11733-8.

10 McCoy DC, Raver CC, Sharkey P. Children's cognitive performance and selective attention following recent community violence. J Health Soc Behav 2015;56:19-36.

11 Bertrand M, Mullainathan S, Shafir E. A behavioral-economics view of poverty. Am Econ Rev 2004;94:419-23.

12 Wallace DJ, Ray KN, Degan A, et al. Transportation characteristics associated with non-arrivals to paediatric clinic appointments: a retrospective analysis of 51580 scheduled visits. BMJ Qual Saf 2018;27:437-44.

13 Costas-Muniz R, Leng J, Aragones A, et al. Association of socioeconomic and practical unmet needs with self-reported nonadherence to cancer treatment appointments in lowincome Latino and Black cancer patients. Ethn Health 2016;21:118-28.

14 Ellis DA, McQueenie R, McConnachie A, et al. Demographic and practice factors predicting repeated non-attendance in primary care: a national retrospective cohort analysis. Lancet Public Health 2017;2:e551-e559.

15 Neal RD, Lawlor DA, Allgar V, et al. Missed appointments in general practice: retrospective data analysis from four practices. Br J Gen Pract 2001;51:830-2.

16 Shojania KG, Dixon-Woods M. 'Bad apples': time to redefine as a type of systems problem? BMJ Qual Saf 2013;22:528-31.

17 Vincent C, Carthey J, Macrae C, et al. Safety analysis over time: seven major changes to adverse event investigation. Implement Sci 2017;12:151.

18 Batalden M, Batalden P, Margolis P, et al. Coproduction of healthcare service. BMJ Qual Saf 2016;25:509-17.

19 Sabadosa KA, Batalden PB. The interdependent roles of patients, families and professionals in cystic fibrosis: a system for the coproduction of healthcare and its improvement. BMJ Qual Saf 2014;23(Suppl 1):i90-4.

20 Thomson R, Murtagh M, Khaw FM. Tensions in public health policy: patient engagement, evidence-based public health and health inequalities. Qual Saf Health Care 2005;14:398-400.

21 Ocloo J, Matthews R. From tokenism to empowerment: progressing patient and public involvement in healthcare improvement. BMJ Qual Saf 2016;25:626-32.

22 Berkowitz SA, Hulberg AC, Hong C, et al. Addressing basic resource needs to improve primary care quality: a community collaboration programme. BMJ Qual Saf 2016;25:164-72.

23 Redelmeier DA, Chan WK, Mullainathan S, et al. Social benefit payments and acute injury among low-income mothers. Open Med 2012;6:e101-8.
24 Bourdeaux CP, Davies KJ, Thomas MJ, et al. Using 'nudge' principles for order set design: a before and after evaluation of an electronic prescribing template in critical care. BMJ Qual Saf 2014;23:382-8.

25 Hawkes N. Finding the techniques to nudge the population to better health. BMJ 2011;342:d389.

26 Patel MS, Volpp KG, Asch DA. Nudge units to improve the delivery of health care. N Engl J Med 2018;378:214-6.

27 Institute of Medicine (IOM). Crossing the quality chasm: a new health system for the 21st century. Washington, DC: National Academy Press, 2001.

28 Institute of Medicine (IOM). In: Kohn LT, Corrigan JM, Donaldson MS, eds. To err is human: building a safer health system. Washington, DC: National Academy Press, 2000.

29 Best M, Neuhauser D. Joseph Juran: overcoming resistance to organisational change. Qual Saf Health Care 2006;15:380-2.

30 Wilcock PM, Thomson RG. Modern measurement for a modern health service. Qual Health Care 2000;9:199-200.

31 Zafar MA, Panos RJ, Ko J, et al. Reliable adherence to a COPD care bundle mitigates system-level failures and reduces COPD readmissions: a system redesign using improvement science. BMJ Qual Saf 2017;26:908-18.

32 Aubert CE, Schnipper JL, Williams MV, et al. Simplification of the HOSPITAL score for predicting 30-day readmissions. BMJ Qual Saf 2017;26:799-805.

33 Carter J, Ward C, Wexler D, et al. The association between patient experience factors and likelihood of 30-day readmission: a prospective cohort study. BMJ Qual Saf 2017:bmjqs-2017-007184.

34 Greysen SR, Harrison JD, Kripalani S, et al. Understanding patient-centred readmission factors: a multi-site, mixedmethods study. BMJ Qual Saf 2017;26:33-41.

35 Santana MJ, Holroyd-Leduc J, Southern DA, et al. A randomised controlled trial assessing the efficacy of an electronic discharge communication tool for preventing death or hospital readmission. BMJ Qual Saf 2017;26:993-1003.

36 van Galen LS, Brabrand M, Cooksley T, et al. Patients' and providers' perceptions of the preventability of hospital readmission: a prospective, observational study in four European countries. BMJ Qual Saf 2017;26:958-69.

37 Born KB, Coulter A, Han A, et al. Engaging patients and the public in Choosing Wisely. BMJ Qual Saf 2017;26:687-91.

38 Chalmers K, Pearson SA, Elshaug AG. Quantifying low-value care: a patient-centric versus service-centric lens. BMJ Qual Saf 2017;26:855-8.

39 Kullgren JT, Krupka E, Schachter A, et al. Precommitting to choose wisely about low-value services: a stepped wedge cluster randomised trial. BMJ Qual Saf 2017.

40 McAlister FA, Lin M, Bakal J, et al. Frequency of low-value care in Alberta, Canada: a retrospective cohort study. BMJ Qual Saf 2017:bmjqs-2017-006778.

41 Dutton DJ, Forest PG, Kneebone RD, et al. Effect of provincial spending on social services and health care on health outcomes in Canada: an observational longitudinal study. CMAJ 2018;190:E66-71.

42 Bradley EH, Elkins BR, Herrin J, et al. Health and social services expenditures: associations with health outcomes. BMJ Qual Saf 2011;20:826-31.

43 Berkowitz SA, Hulberg AC, Standish S, et al. Addressing unmet basic resource needs as part of chronic cardiometabolic disease management. JAMA Intern Med 2017;177:244-52. 